\title{
SOSIALISASI DAN PELATIHAN IDENTIFIKASI SIPUT GONGGONG SECARA MORFOLOGI PADA MASYARAKAT KAMPUNG MADUNG, TANJUNGPINANG
}

\section{Socialization And Training Identification Of Gender The Dog Conch Only Morphology In Madung Society, Tanjungpinang}

\author{
Susiana $^{1 *}$, Dedy Kurniawan ${ }^{1}$, Azwin Apriandi ${ }^{2}$, Nurleni $^{1}$ \\ ${ }^{1}$ Jurusan Manajemen Sumberdaya Perairan, FIKP, Universitas Maritim Raja Ali Haji \\ ${ }^{2}$ Jurusan Teknologi Hasil Perikanan, FIKP, Universitas Maritim Raja Ali Haji \\ *Korespondensi : susiana@umrah.ac.id
}

\begin{abstract}
ABSTRAK
Siput gonggong telah dikenal sebagai ikon Kepulauan Riau. Sampai saat ini, permintaan pasar akan siput gonggong terus berlanjut. Hal ini dibuktikan masih tersedianya stok siput gonggong baik yang masih bercangkang maupun dagingnya saja di pasar, rumah makan dan di pinggir-pinggir jalan. Peminat kuliner siput gonggong tidak hanya masyarakat setempat tetapi juga para pendatang/wisatawan dari luar. Dengan permintaan pasar yang semakin hari terus berlanjut, membuat nelayan penangkap siput gonggong hampir setiap hari menangkap untuk memenuhi permintaan pasar tersebut. Sehingga keberlanjutan populasi di alam diduga mengalami kondisi kritis yaitu penangkapan berlebihan (over fishing). Saat ini, munculnya fenomena ukuran gonggong yang tertangkap semakin kecil jika dibandingkan beberapa tahun yang lalu. Hal ini lah yang melatarbelakangi betapa pentingnya pengetahuan identifikasi jenis kelamin siput gonggong yang harus diberikan kepada masyarakat agar stok di alam dapat kembali pulih. Tujuan dari kegiatan pengabdian masyarakat ini adalah agar kelompok masyarakat dapat melakukan pengidentifikasian secara langsung di alam sehingga masyarakat pada akhirnya bisa lebih selektif dalam melakukan penangkapan siput gonggong jantan dan siput gonggong betina agar ketersediaan stok siput gonggong dapat berkelanjutan. Upaya untuk mencapai keberhasilan dalam usaha mempertahankan keberadaan siput gonggong secara kontinyu maka tingkat pengetahuan kelompok masyarakat harus ditingkatkan dengan melakukan pendekatan sosial, pendampingan dan pelatihan serta keterampilan. Dengan pemberian informasi yang jelas tentang langkah-langkah dan tahap dalam identifikasi jenis kelamin siput gonggong secara morfologi.
\end{abstract}

Kata kunci : sosialiasasi, pelatihan, identifikasi jenis kelamin, siput gonggong, morfologi

\begin{abstract}
Dog conch has been known as the iconic Riau islands. To date, the market demand for the dog conch continues. It is evidenced that there is still the availability of a good stock of dog conch slugs that are still chatting and the flesh alone in the market, restaurant and on the roadside. The culinary enthusiasts of dog conch not only the local people but also the foreigners/tourists from outside. With the demand of the market continuing the day continues, making the fishermen dog conch almost every day catching to meet the demands of the market. So that the sustainability of the population in nature is suspected critical condition of overfishing. Today, the emergence of the dog conch size phenomenon is caught smaller than a few years ago. This is the background of the importance of the knowledge of the sex dog conch that should be given to the community so that the stock in nature can recover again. The purpose
\end{abstract}


of this community dedication is that the community can do direct identification in nature so that the community can eventually be more selective in carrying out male gonggong slugs and slugs Female dog conch for the availability of gonggong snail stock can be sustainable. Efforts to achieve success in the effort to maintain the existence of the dog conch continuously, the level of knowledge of community groups should be improved by conducting social approaches, mentoring and training as well as skills. By providing clear information about the steps and stages in identifying the sex of the dog conch morphologically.

Keywords: socialization, training, gender identification, dog conch, morphology

\section{PENDAHULUAN}

Siput gonggong atau lebih dikenal sebagai dog conch merupakan gastropoda laut dari famili Strombidae (Carpenter and Niem, 1998). Menurut Muzahar and Hakim (2018) secara ekonomi diantaranya daging siput gonggong dimanfaatkan sebagai bahan makan. Siput gonggong telah lama menjadi objek tangkapan oleh kelompok Madung karena selalu ada permintaan akan siput gonggong setiap hari. Hasil tangkapan dari nelayan di jual langsung di pasar dan rumah makan. Kedua tempat tersebut selalu menjadi perioritas penjualan daripada hasil tangkapan dikonsumsi oleh nelayan.

Permasalahan pada kelompok nelayan siput gonggong yaitu dalam pengetahuan dan keterampilan dalam mengidentifikasi jenis kelamin siput gonggong. Kemampuan dalam mengidentifikasi jenis kelamin secara morfologi siput gonggong belum diketahui oleh kelompok ini.

Permasalahan yang terjadi kepada kelompok mitra adalah masih terbatasnya pengetahuan dan keterampilan (skill) yang dimiliki dalam mengidentifikasi jenis kelamin siput gonggong secara morfologi di alam. Hal utama yang menjadi perioritas adalah menemukan ciri-ciri seksualitas sekunder siput gonggong sehingga gejala penangkapan berlebihan (overfishing) di alam dapat di tekan dengan pengambilan atau penangkapan khusus terhadap siput gonggong jenis kelamin jantan saja, sehingga siput gonggong betina mempunyai peluang untuk melakukan pemijahan demi keberlanjutan stok di alam.

Penyelesaikan permasalahan di atas membutuhkan solusi yang tepat sasaran. Beberapa solusi untuk memecahkan permasalahan tersebut adalah memberikan pelatihan dasar kepada mitra tentang ciriciri seksualitas sekunder pada siput gonggong betina dan siput gonggong jantan secara morfologi (penampakan luar) dari bentuk cangkang, warna, ukuran tubuh.

Manfaat yang akan dicapai dari kegiatan pendampingan yang direncanakan seperti masyarakat mengetahui dengan jelas bagaimana proses dasar dalam mengindentifikasi jenis kelamin siput gonggong secara morfologi, masyarakat memiliki kemampuan khusus dalam membedakan siput gonggong jantan dan siput gonggong betina langsung di alam dan masyarakat memiliki kesadaran akan keberlanjutan stok siput gonggong di alam, sehingga dalam melakukan penangkapan lebih selektif baik dari segi jenis kelamin dan ukuran tubuh siput gonggong.

\section{METODE}

\section{Waktu dan Tempat}

Kegiatan pengabdian kepada masyarakat ini dilaksanakan pada bulan Juli hingga September 2019 yang berlokasi di Kampung Madung, Tanjungpinang.

\section{Prosedur Pelaksanaan dan Analisis Data}

Metode pelaksanaan dalam kegiatan ini adalah melakukan pendampingan langsung ke masyarakat dalam menggali pengetahuan dasar secara khusus tentang 
Tabel 1. Urutan tahapan yang akan dilakukan pada pengabdian masyarakat

\begin{tabular}{|c|c|}
\hline $\begin{array}{c}\text { Urutan } \\
\text { Tahapan }\end{array}$ & Kegiatan \\
\hline 1. & Melakukan kunjungan kepada masyarakat sebagai sosialisasi awal \\
\hline 2. & $\begin{array}{l}\text { Melakukan indentifikasi permasalahan yang lebih aktual serta } \\
\text { identifikasi lokasi pelaksanaan pelatihan. }\end{array}$ \\
\hline 3. & Mempersiapkan alat dan bahan untuk pelatihan \\
\hline 4. & Melakukan sosialisasi mengenai daur hidup siput gonggong \\
\hline 5. & $\begin{array}{l}\text { Melakukan pengajaran mengenai habitat dan kebiasaan makan seperti } \\
\text { yang dikemukakan oleh Sugiarti et al. (2005) dalam Siddik (2011) yaitu } \\
\text { siput gonggong mencari makan secara deposit feeder, yaitu menyapu dan } \\
\text { menyedot endapan di dasar Perairan yang berasosiasi dengan lamun } \\
\text { (Enhalus accoroides) dan Thalassia sap. }\end{array}$ \\
\hline 6. & $\begin{array}{l}\text { Melakukan pengajaran mengenai waktu yang baik dalam penangkapan } \\
\text { siput gonggong berdasarkan siklus reproduksinya. Puncak pemijahan siput } \\
\text { gonggong (Laevistrombus turturella) di Tl. Klabat terjadi pada bulan Mei } \\
\text { dan Oktober (Dody, 2009) }\end{array}$ \\
\hline 7. & $\begin{array}{l}\text { Melakukan pelatihan dalam membedakan jenis kelamin siput gonggong } \\
\text { dengan cara memecahkan cangkangnya (secara anatomi). Kebanyakan } \\
\text { gastropoda bersifat dioseous dengan sebuah gonad (ovari atau testis) } \\
\text { terletak dekat saluran pencernaan dalam massa visera (Barnes, } 1994 \\
\text { dalam Siddik, J., 2011) }\end{array}$ \\
\hline 8. & $\begin{array}{l}\text { Melakukan pelatihan dan pendampingan dalam menentukan gonad siput } \\
\text { gonggong betina dan siput gonggong jantan. Namun, gonad jantan dan } \\
\text { betina hampir sama selama hidupnya masa juvenil, muncul jaringan tipis } \\
\text { coklat pucat di kelenjar pencernaan. Berikutnya ada perubahan dalam } \\
\text { warna gonad ketika mereka matang: dari kehitaman menjadi krim atau } \\
\text { kuning pucat ke kuning kecoklatan atau oranye terang ditahap dewasa } \\
\text { (Cod, Z. C et al., 2008a). Siput gonggong jantan mencapai tingkat } \\
\text { kematangan awal lebih pendek ukurannya dibandingkan dengan siput } \\
\text { betina (Dody, 2008). }\end{array}$ \\
\hline 9. & $\begin{array}{l}\text { Melakukan pengajaran, pelatihan dan pendampingan dalam membedakan } \\
\text { seksualitas sekunder siput gonggong jantan dan siput gonggong betina dari } \\
\text { aspek warna, ukuran, tekstur cangkang (secara morfologi) }\end{array}$ \\
\hline
\end{tabular}

siput gonggong dan permasalahan serta kendala yang dihadapi untuk menentukan langkah-langkah yang lebih tepat dalam menyelesaikan permasalahan yang terjadi di lapangan dan dianalisis secara deskriptif.

Berkurangnya hasil tangkapan nelayan disebabkan oleh beberapa faktor seperti penangkapan siput gonggong yang tidak selektif yang dilakukan tanpa adanya pembatasan ukuran dan waktu. Selain itu, kurangnya pengetahuan tentang jenis kelamin siput gonggong jantan dan siput gonggong betina sehingga tidak ada peluang untuk melakukan pemijahan.
Salah satu parameter reproduksi untuk menentukan kemungkinan tersedianya induk jantan dan induk betina agar terjadi pemijahan adalah nisbah kelamin (Rochmady, 2011). Selain itu, nisbah kelamin menunjukkan adanya eksploitasi yang berlebihan terhadap salah satu jenis kelamin (Effendie, 1997; Rochmady et al., 2013), maupun indikasi adanya perubahan lingkungan (Susiana et al., 2013, 2017). 


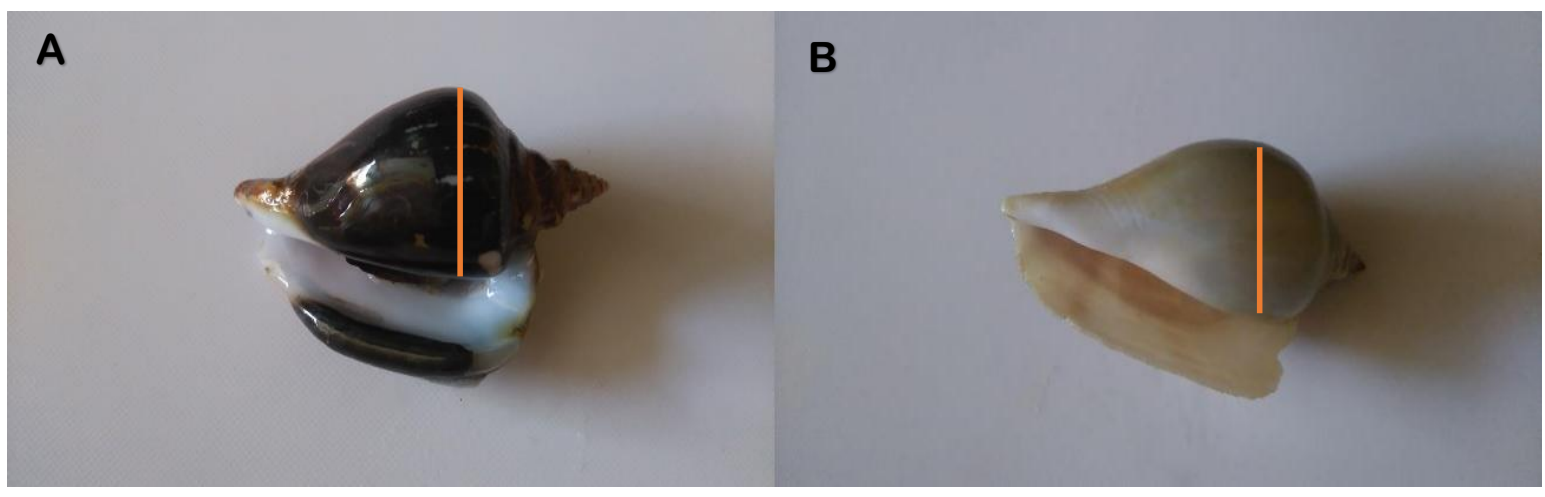

Gambar 1. Bentuk cangkang lebar untuk siput gonggong jenis kelamin betina (A) dan (B),

HASIL DAN PEMBAHASAN

\section{Identifikasi Jenis Kelamin}

Identifikasi jenis kelamin secara morfologi dilihat dari kajian struktur cangkang, warna, bukaan cangkang (aperture) dan panjang cangkang. Bentuk cangkang siput gonggong ditemukan memiliki postur/bentuk berbeda, yakni postur cangkang lebar dan langsing dari kedua spesies yang ditemukan. Cangkang dengan bentuk lebar secara morfologi menandakan siput gonggong dengan jenis kelamin betina (Gambar ). Sedangkan cangkang dengan bentuk lebih langsing menandakan siput gonggong jenis kelamin jantan (Gambar ). Hal ini telah dibuktikan dengan mengeluarkan daging gonggong untuk melihat jenis kelamin secara morfologi (Gambar dan Gambar ).

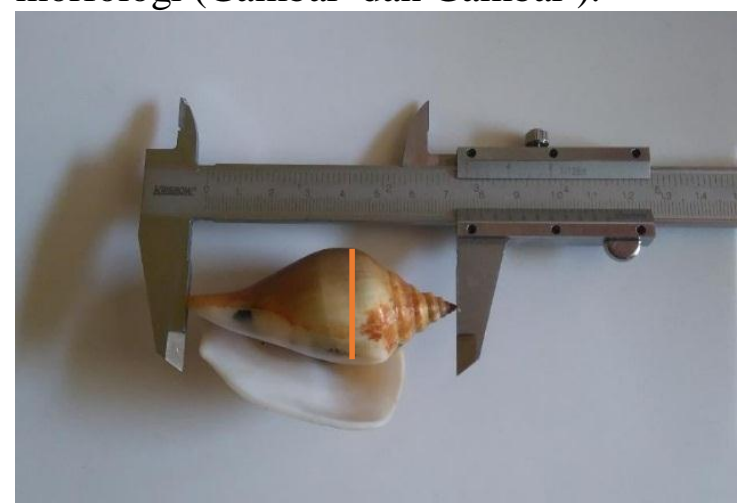

Gambar 2. Bentuk cangkang langsing untuk siput gonggong jenis kelamin jantan.

Keterangan: merupakan tanda identifikasi secara morfologi yang digunakan.

Warna cangkang pada siput gonggong bervariasi dari kehitaman, kecoklatan, kuning keemasan, krem, dan putih (Gambar dan Gambar ). Dari warna cangkang sulit membedakan jenis kelamin siput gonggong. Bukaan cangkang (aperture) siput gonggong ada yang dangkal dan ada yang melebar. Bukaan cangkang yang melebar biasanya siput gonggong tersebut telah memasuki masa pemijahan. Hal ini sebagaimana yang dikemukan oleh Davis (2005) dan Dody (2012), bahwa siput strombus (Strombus gigas) dewasa memiliki kelamin terpisah dan akan mengalami kematangan seksual setelah tepi luar cangkangnya (lip) berkembang secara penuh. Dengan demikian pendekatan warna cangkang dan bukaan cangkang sulit dijadikan sebagai indikator perbedaan jenis kelamin jantan dan betina.

Analisis secara morfologi akan dilanjutkan dengan konfirmasi secara anatomi (Gambar dan Gambar ). Setelah dilakukan pengamatan bentuk cangkang, untuk mendapatkan hasil yang lebih akurat yaitu dengan membuktikan jenis kelamin siput gonggong secara anatomi. Adapun secara anatomi, bisa dibedakan dari organ reproduksi siput gonggong yakni adanya tonjolan untuk jenis kelamin jantan (Dody, 2012). Perbedaan secara mencolok antara jenis kelamin jantan dan betina secara anatomi dapat diihat pada Gambar dan Gambar . Pada Gambar A dan B yang diberi tanda lingkaran (O) memperlihatkan dengan jelas adanya tanda khusus pada jenis kelamin jantan. Sedangkan pada jenis kelamin betina (Gambar ) tidak menunjukkan adanya 


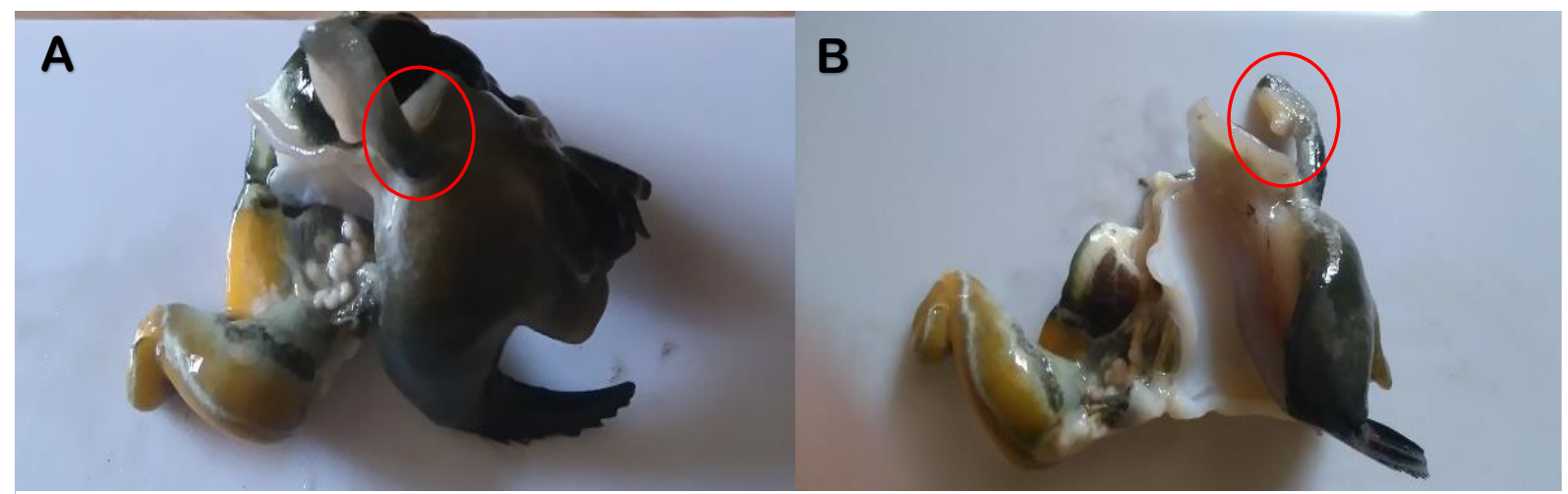

Gambar 3. Organ reproduksi siput gonggong jenis kelamin jantan berupa tonjolan.

Keterangan: tanda $\mathrm{O}$ menunjukkan tonjolan yang dimaksud.

tanda khusus berupa tonjolan (Reed, 1991; Widyastuti dan Aji, 2016). Hal ini secara jelas memberikan informasi bahwa pada postur cangkang langsing menunjukkan jenis kelamin jantan, sedangkan pada postur cangkang lebar menunjukkan jenis kelamin betina.

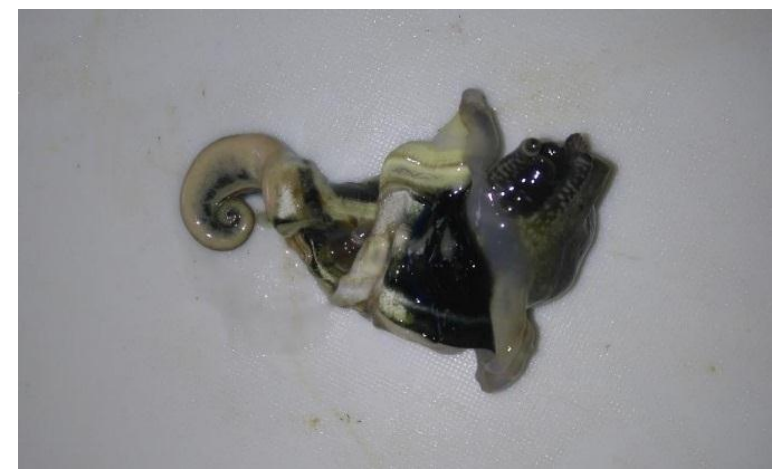

Gambar 4. Tidak ada tonjolan pada organ reproduksi siput gonggong betina di perairan Madung, Tanjungpinang, Indonesia

\section{Pelatihan dan Pendampingan Identifikasi Jenis}

Adapun kegiatan yang telah dilakukan adalah sebagai berikut:

1. Melakukan kunjungan kepada kelompok masyarakat yang ada di Kampung Madong, Kota Tanjungpinang sebagai tahap awal sosialisasi,

2. Melakukan wawancara dengan masyarakat untuk mengindentifikasi permasalahan yang lebih aktual, serta melakukan koordinasi untuk menentukan lokasi pelaksanaan pelatihan,

3. Melakukan rapat untuk mempersiapkan alat dan bahan untuk pelatihan, serta mempersiapkan bahan persentasi untuk pelatihan,

4. Melakukan sosialisasi mengenai daur hidup siput gonggong,

5. Melakukan pengajaran mengenai habitat dan kebiasaan makan seperti yang dikemukakan oleh Sugiarti et al. (2005) dalam Siddik (2011) yaitu siput gonggong mencari makan secara deposit feeder, yaitu menyapu dan menyedot endapan di dasar Perairan yang berasosiasi dengan lamun (Enhalus accoroides) dan Thalassia sp.,

6. Melakukan pengajaran mengenai habitat dan kebiasaan makan seperti yang dikemukakan oleh Sugiarti et al. (2005) dalam Siddik (2011) yaitu siput gonggong mencari makan secara deposit feeder, yaitu menyapu dan menyedot endapan di dasar Perairan yang berasosiasi dengan lamun (Enhalus accoroides) dan Thalassia sp.

7. Melakukan pengajaran mengenai waktu yang baik dalam penangkapan siput gonggong berdasarkan siklus reproduksinya. Puncak pemijahan siput gonggong (Laevistrombus turturella) di Tl. Klabat terjadi pada bulan Mei dan Oktober (Dody, 2009),

8. Melakukan pelatihan dalam membedakan jenis kelamin siput 
gonggong dengan cara memecahkan cangkangnya (secara anatomi). Kebanyakan gastropoda bersifat dioseous dengan sebuah gonad (ovari atau testis) terletak dekat saluran pencernaan dalam massa visera (Barnes, 1994 dalam Siddik, J., 2011),

9. Melakukan pelatihan dan pendampingan dalam menentukan gonad siput gonggong betina dan siput gonggong jantan. Namun, gonad jantan dan betina hampir sama selama hidupnya masa juvenil, muncul jaringan tipis coklat pucat di kelenjar pencernaan. Berikutnya ada perubahan dalam warna gonad ketika mereka matang: dari kehitaman menjadi krim atau kuning pucat ke kuning kecoklatan atau oranye terang ditahap dewasa (Cod, Z. C et al., 2008a). Siput gonggong jantan mencapai tingkat kematangan awal lebih pendek ukurannya dibandingkan dengan siput betina (Dody, 2008),

10. Melakukan pengajaran, pelatihan dan pendampingan dalam membedakan seksualitas sekunder siput gonggong jantan dan siput gonggong betina dari aspek warna, ukuran, tekstur cangkang (secara morfologi),

\section{KESIMPULAN}

Pengabdian kepada masyarakat Pemberdayaan Kelompok Masyarakat melalui Pelatihan Keterampilan dalam Identifikasi Jenis Kelamin secara Morfologi di Kampung Madung, Kota Tanjungpinang telah dapat dilakukan dengan baik. Dengan kerjasama tim pengabdian dan peran aktif masyarakat, maka kegiatan pengabdian berjalan sesuai harapan dan kedepannya dapat memberikan manfaat bagi masyarakat Kampung Madong Kota Tanjungpinang dalam memanfaatkan hasil tangkapan siput gonggong.

Pengabdian yang kami lakukan telah sampai pada tahapan pelatihan keterampilan mengindentifikasi jenis kelamin siput gonggong secara morfologi, sehingga dapat membedakan siput gonggong jantan dan siput gonggong betina langsung di alam berdasarkan pada bentuk cangkang (lebar dan langsing). Siput gonggong dengan cangkang lebar menandakan jenis kelamin betina, sementara bentuk cangkang langsing menandakan jenis kelamin jantan.

\section{UCAPAN TERIMA KASIH}

Terima kasih kepada Universitas Maritim Raja Ali Haji atas pendanaan Pengabdian Kepada Masyarakat tahun 2019.

\section{DAFTAR PUSTAKA}

Cob, Z. C., Arshad, A., Bujang, J. S dan Gaffar, M.A. (2008a). Sexual maturity and Sex Determination in Strombus canarium Linnaeus, 1758 (Gastropoda: Strombidae). Journal of Biological Sciences, 8(3): 616-621.

Dody, S. 2008. Pemulihan kondisi populasi Siput Gonggong (Strombus turturella) di Teluk Klabat, Bangka Belitung. Laporan Akhir Kegiatan Program Kompetitif LIPI. Dipa

Dody, S. 2009. Habitat dan Sebaran Spasial Siput Gonggong (Strombus turturella) di Teluk Klabat, Bangka Belitung. Prosiding Seminar Nasional Moluska dalam Penelitian, Konservasi dan Ekonomi. Pusat Penelitian Oseanografi LIPI. Jakarta. $100 \mathrm{hlm}$.

Davis, M. 2005. Speces Profile: Queen Conch, Strombus gigas. Southern Regional Aquaculture Center. 111p.

Dody, S. 2012. Pemijahan dan perkembangan larva siput gonggong (Strombus turturella). Jurnal Ilmu dan Teknologi Kelautan Tropis, 4(1):107-113. doi:10.29244/jitkt.v4i1.7811.

Effendie, M.I. 1997. Biologi Perikanan. 
Yayasan Pustaka Nusatama.

Yogyakarta. 163p.

Muzahar, and A.A. Hakim. 2018. Spawning and development of dog conch Strombus sp. larvae in the laboratory. Jurnal Ilmu dan Teknologi Kelautan Tropis, 10(1):209-216. doi:10.29244/jitkt.v10i1.18607.

Reed, S.E.1991. Reproductive Anatomy and Biology of the Genus Strombus in the Caribbean: I. Males. In: Proceeding of the 44th Gulf and Caribbean Fisheries Institute,. pp. 427-438.

Rochmady, R., S.B.A. Omar, dan L.S. Tandipayuk. 2013. Nisbah kelamin dan ukuran pertama matang gonad kerang lumpur (Anodontia edentula, Linnaeus 1758) di pesisir Lambiku, Kecamatan Napabalano Kabupaten Muna. Agrikan: Jurnal Agribisnis dan Perikanan, 6(1):1-9. doi:10.29239/j.agrikan.6.1.1-9.

Siddik, J. 2011. Sebaran Spasial dan Potensi Reproduksi Populasi Siput
Gonggong (Strombus turturella) di Teluk Klabat Bangka-Belitung. Tesis. IPB: Bogor

Susiana, S., A. Niartiningsih, dan M.A. Amran. 2013. Kelimpahan dan kepadatan kima (Tridacnidae) di Kepulauan Spermonde. Agrikan: Jurnal Agribisnis Perikanan, 6(5):55-61. doi:10.29239/j.agrikan.6.0.55-61.

Susiana, S., A. Niartiningsih, M.A. Amran, and R. Rochmady. 2017. Suitability of location for restocking clams Tridacnidae in the Spermonde Archipelago. Jurnal Ilmu dan Teknologi Kelautan Tropis, 9(2):475-490. doi:10.29244/jitkt.v9i2.19284.

Widyastuti, A. dan L.P. Aji. 2016. Beberapa aspek reproduksi siput Lambis lambis di Pesisir Perairan Yenusi, Biak. Oseanologi dan Limnologi di Indonesia, 1(3):1-9.

Diterima : 18 September 2019

Disetujui : 11 November 2019 